\title{
Elites Científicas do Clima: Formação do CAMPo EM ESCALA NACIONAL E INTERNACIONAL
}

\author{
Thales Haddad Novaes de ANDRADE*
}

\begin{abstract}
RESUMO: O presente artigo pretende discutir a importância das ciências do clima e sua conformação atual, defendendo que é importante retomar a temática das elites científicas para entender os rumos atuais da discussão sobre mudanças climáticas. A abordagem de Bourdieu sobre a temática do campo científico e as formas de acumulação de capital auxilia na compreensão das alterações das ciências meteorológicas frente aos desafios mais recentes das mudanças climáticas nas últimas décadas. $\mathrm{O}$ texto analisa o desenvolvimento das ciências do clima em escala internacional e o papel desempenhado pelo International Panel for Climate Change (IPCC) na redistribuição dos créditos científicos consagrados na área. Ao final o texto trata do modo como as elites brasileiras vêm se reorganizando para se situar frente aos setores hegemônicos internacionais que comandam a agenda de pesquisa sobre mudanças climáticas.
\end{abstract}

PALAVRAS-CHAVE: Elites científicas. Ciências climáticas. Campo científico. Mudanças climáticas.

Introdução

Cientistas são agentes importantes na definição da agenda climática. É difícil discutir os impactos e as implicações das mudanças climáticas sem levar em conta os argumentos e as evidências científicas. Atualmente, um aspecto incontroverso da temática das mudanças climáticas é o peso do posicionamento dos cientistas e das instituições científicas.

Diversos estudos têm explorado o surgimento e as práticas científicas envolvidas nos estudos das mudanças climáticas. Pesquisadores da área de estudos sociais de ciência e tecnologia têm apontado o tema das mudanças climáticas como exemplar para se entender a nova conformação das práticas de pesquisas científicas (VESSURI \& ROSE, 2010).

\footnotetext{
* UFSCar - Universidade Federal de São Carlos. Departamento de Ciências Sociais. São Carlos - SP Brasil.13565-905. thales@ufscar.br. https://orcid.org/0000-0002-4000-3527.
} 
Percebe-se um forte viés nas preocupações sobre as controvérsias científicas envolvidas nas pesquisas sobre mudanças climáticas (VELTRONE, 2017; MIGUEL, 2017; LEITE, 2015; BAILÃO, 2014; NEVES \& LIMA, 2012; SUNDBERG, 2005).

Diversos autores de diferentes referenciais teóricos têm discutido a interferência do comportamento dos cientistas no estabelecimento dessa agenda de pesquisa sobre mudanças climáticas (LEITE, 2015; ORESKES \& CONWAY, 2010; NOBLE, 2009; YEARLEY, 2009; SUNDBERG, 2005). Sem dúvida, a atuação dos cientistas em suas articulações profissionais e políticas têm promovido um conjunto de arranjos da discussão da ciência climática que precisa ser debatido em novas perspectivas.

Várias pesquisas têm sido feitas sobre a importância dos modelos numéricos e recursos informacionais para a produção de conhecimento climático confiável e reconhecido. A modelagem climática se impôs como conhecimento imprescindível para a previsão de tendências meteorológicas através de simulações e projeções, o que proporciona uma série de implicações para a prática científica (HULME, 2013; LAHSEN, 2005).

Apesar da importância dessas análises sobre controvérsias e práticas para a compreensão da atuação dos cientistas climáticos, percebe-se que é necessário investir na análise das coalizões dominantes dessa agenda científica.

O presente estudo se propõe a considerar esse aspecto na análise da ciência do clima. A atuação das elites científicas nos estudos climáticos e suas estratégias de controle dessa agenda é também um aspecto importante, tanto para a sociologia da ciência, como para os estudos ambientais. Para além das controvérsias científicas, são também travadas batalhas reputacionais no interior do campo científico que produzem transformações nas hierarquias acadêmicas estabelecidas e redirecionam as pesquisas sobre mudanças climáticas.

Segundo a perspectiva de Whitley (2009), em virtude de uma série de mudanças organizacionais processadas no ambiente universitário dos países centrais, a ciência contemporânea atravessa uma reconfiguração de suas elites e seus respectivos capitais simbólicos. Para assegurar sua condição reputacional, os cientistas precisam mobilizar uma série de tarefas interdependentes e funcionalmente relevantes que funcionam como parâmetros de cientificidade. Nesse sentido, Whitley (1977) não reconhece a existência de padrões disciplinares rígidos na configuração da prática científica recente, o que abre espaço para a predominância de tarefas incertas e cambiantes no universo organizacional da ciência.

O capital científico estabelecido internacionalmente vem redefinindo as modalidades de circulação dos conhecimentos e métodos tradicionais. $\mathrm{O}$ cruzamento entre áreas de formação, atuação departamental, grupos de pesquisa e fontes de 
financiamento mostra que o cenário científico contemporâneo cria uma rede complexa de áreas de especialização em que as fronteiras convencionais não explicam como os grupos hegemônicos se articulam e reproduzem. O pensamento de Pierre Bourdieu (2004, 1983) auxilia na compreensão de como o capital científico se redistribui no campo da ciência à medida que uma área de conhecimento vai se estabelecendo internacionalmente. Os setores dominantes de uma determinada disciplina em consolidação controlam as fórmulas de consagração e as métricas de avaliação que permitem a ampliação das práticas de conhecimento legitimadas.

Nos últimos anos alguns autores vêm apontando que os grupos dominantes da ciência, em escala internacional e que usufruem de capital científico para impor suas versões do debate climático, vêm, desde os anos de 1990, reelaborando suas estratégias de consagração e busca de notoriedade acadêmica (HULME, 2013; EDWARDS, 2010; SCHOIJET, 2008; SUNDBERG, 2005; MILLER, 2004).

Essas elites do clima estão adotando conformações e fórmulas de convergência que precisam ser discutidas em outras bases. $\mathrm{O}$ interesse fundamental desse artigo consiste em apontar quais são as estratégias das elites científicas que participam mais ativamente do debate climático no âmbito brasileiro e internacional. Para uma discussão sobre a temática das elites na sociologia contemporânea, ver Saint Martin (2008).

De início será feita uma discussão sobre o surgimento das ciências climáticas e sua institucionalização. A seguir tem-se um debate acerca das implicações em termos do comportamento de suas respectivas elites e setores hegemônicos. Na sequência optou-se por tratar o caso do International Panel for Climate Change (IPCC) (Painel Intergovernamental sobre Mudanças Climáticas) e sua configuração enquanto arena hegemônica de distribuição de capital científico da área climática.

A partir de então será mostrado como as instituições científicas brasileiras e suas lideranças disciplinares ocuparam os espaços de consagração do campo em forte sintonia com os grupos hegemônicos internacionais. Com isso apresenta-se um panorama das principais convergências científicas estabelecidas para a agenda climática internacional e suas implicações nacionais, com o objetivo de mostrar como o estudo das elites do campo científico fornece instrumental para entender as formas de acumulação de capital científico na área do clima.

\section{O surgimento dos estudos climáticos}

Ao longo do século XX as discussões sobre concentração de gases e mudanças nos padrões atmosféricos receberam um tratamento mais sistematizado. Isso se deu 
devido a diversos fatores: a disponibilidade de dados atmosféricos em escala planetária, o que só foi possível graças ao desenvolvimento de grandes bancos de dados informatizados. Também o desenvolvimento de computadores potentes e os Modelos de Circulação Global permitiram a simulação de processos físicos, químicos e biológicos que antes não eram detectáveis (DESSAI \& TRIGO, 2001).

Esses equipamentos informáticos e o desenvolvimento de modelos matemáticos de alta precisão permitiram o armazenamento de um conjunto diferenciado de dados climáticos. O cruzamento entre informática, modelagem e meteorologia facilitou o desenvolvimento de equipamentos e metodologias de análise que se legitimaram fortemente junto às organizações científicas e governos das grandes potências.

Devido a esses fatores conjugados, as Ciências da Terra ganham forma saliente a partir do pós-guerra, especialmente nos EUA. Uma área científica que surge nesse momento com forte investimento estatal é a geofísica.

Essa área passa a receber grandes investimentos governamentais, devido à sua importância estratégica para fins militares (confecção de satélites e sensoriamento) (DOEL, 2003). Os estudos atmosféricos começam a receber os efeitos do cruzamento entre áreas militares, governamentais, agrícolas e propriamente acadêmicos para o aprimoramento de equipamentos de medição e previsão de eventos físicos e climáticos.

Entre as décadas de 1950 e 1980, as discussões climáticas em termos científicos foram em grande parte controladas pela agenda dos setores militares no contexto da Guerra Fria. Cientistas de renome em suas respectivas áreas estabeleceram interfaces com líderes militares bem posicionados no Departamento de Defesa americano e alavancaram o conhecimento sobre fenômenos ainda pouco visíveis, como concentração de gases, efeitos da radiação e padrões atmosféricos.

Após a Segunda Guerra Mundial, os fundos de pesquisa das Ciências da Terra foram direcionados para atividades de confronto visando intervenção em países em conflito e detecção de ameaças vindas de áreas inimigas (HAMBLIN, 2013).

O físico John von Neumann foi um expoente importante desses novos estudos meteorológicos com a criação do computador digital que seria capaz, segundo ele, de prever e controlar o tempo como instrumento de guerra contra a URSS. Em seus projetos ele pretendia articular teoria física, modelização numérica, informática e estudos atmosféricos de modo a produzir previsões contínuas e eficientes para os setores administrativos americanos para prevenção e antecipação de ataques externos (HAMBLIN, 2013).

Durante os anos de 1950 foi criada a Unidade Conjunta de Previsão Numérica do Tempo, articulando importantes universidades e importantes setores militares da Marinha e Força Aérea. A climatologia nunca mais seria a mesma com a entrada em 
cena da modelagem numérica feita por computadores avançados e medições novas dos índices de concentração de carbono.

A incerteza dos achados científicos e a imponderabilidade dos movimentos dos países soviéticos tornavam essas pesquisas mais abertas e imprevisíveis, formando um caldo de achados e perspectivas de conhecimento em aberto e em sintonia com os interesses geopolíticos americanos. De acordo com a análise de Leite (2015):

Os climatologistas buscavam não mais as regularidades estatísticas no clima, mas simular o clima com modelos semelhantes aos utilizados na previsão numérica do tempo, incorporando neles conclusões dos estudos físico-químicos da atmosfera, tais como as do ciclo do carbono. Tratava-se, também, diferentemente da meteorologia da primeira metade do século XX, [...] de uma disciplina, em grande medida, modulada pela atuação de pesquisadores norte-americanos, associandose, na segunda metade do século XX, a influências específicas do contexto estadunidense, com projeções para áreas de cultura anglo-saxãs (a Guerra Fria, o programa espacial, o desenvolvimento e disponibilidade de computadores etc.). (LEITE, 2015, p 648).

A dependência para com a agenda militar da Guerra Fria e com os equipamentos oriundos da informática montaram uma coalizão científica nacionalista, norteamericana, conservadora e episódica, destituída de um arcabouço organizacional duradouro que sustentasse projetos de longo prazo.

Essa readequação da formulação teórica e da compreensão das dinâmicas climáticas para caberem nos mecanismos computacionais indica uma contingência da produção científica aos imperativos instrumentais dos laboratórios e suas capacidades técnicas de armazenamento e combinação de resultados, na forma de big data ou outros dispositivos semelhantes.

Nesse sentido, a produção científica confiável na área climática é aquela que dispõe dos aparatos instrumentais mais sofisticados e atualizados, fazendo convergir a competência científica com qualidade instrumental. E, segundo a formulação de Bourdieu (1983), garantindo e mantendo o capital científico consagrado da área nas mãos dos grandes centros de excelência capazes de se atualizarem com equipamentos e softwares de última geração.

Em outro aspecto correlacionado ao anterior, nota-se o distanciamento dos cientistas da realidade empírica e sua relativização. Uma vez que esses cientistas denominados modelistas trabalham com modelos computadorizados, corre-se o risco desses modelos refletirem mais as condições dos equipamentos disponíveis (softwares, gráficos) do que a realidade climática propriamente dita. 
Um dos autores que apontam esse problema no interior da comunidade climática é Mayanna Lahsen (2005). Em sua pesquisa sobre a construção de modelos para os estudos climáticos, a autora aponta alguns resultados interessantes. Entrevistando determinados modelistas responsáveis pela construção e interpretação dos modelos computacionais, ela detecta uma grande dificuldade desses cientistas em se afastarem de seus pressupostos e das condições das ferramentas usadas.

De acordo com as falas dos modelistas climáticos, eles demonstram estar cientes da distância que existe entre o objeto empírico estudado e suas ferramentas de análise, e reconhecem que gastam mais tempo ajustando e reprogramando estas ferramentas do que com o objeto estudado, admitindo o perigo de confundirem a realidade do modelo com o mundo real modelado.

A utilização recorrente desses modelos e sua legitimidade crescente suscitam vários outros debates no interior das ciências climáticas. A validade dos estudos depende da capacidade de se ordenar e abarcar uma maior quantidade de variáveis, o que não é de todo óbvio.

Segundo Bessat (2003), as controvérsias em torno da aplicação de modelos matemáticos ao se lidar com escalas regionais são extremamente relevantes:

Para que este estudo seja bem-sucedido, convém dispor de ferramentas eficientes, capazes de analisar com eficácia e credibilidade o sistema climático e, em particular, a incidência de emissões antrópicas de gases de efeito estufa e dos aerossóis sobre as modificações da composição da atmosfera. Ora, os modelos são mais ou menos representativos, segundo o número de componentes que integram. Assim, um modelo pode simular somente a atmosfera, enquanto outros, mais completos, combinarão a atmosfera (e as reações químicas que nela intervém), o oceano e as biosferas terrestre e marinha. Considera-se, hoje, que o realismo das simulações climáticas fica cada vez melhor devido à precisão da resolução. Entretanto, os limites de cálculos não permitem atingir uma resolução satisfatória, que dê conta de todos os processos e, em particular, dos inferiores, como a formação das nuvens e suas interações com a radiação atmosférica ou as trocas entre a atmosfera e a biosfera. (BESSAT, 2003, p.15).

Em outras palavras, é difícil determinar eficazmente a quantidade necessária de informação para se entender às interações climáticas e às interferências regionais no estabelecimento dos modelos. Um geógrafo pode listar variáveis que interagem com os modelos climáticos e que, por sua vez, podem não caber na formatação dos modelos existentes.

Esses modelos são aceitos cientificamente e de fato possibilitam estabelecer 
padrões e tendências recorrentes dos fenômenos climáticos, o que é relevante para se estabelecer práticas de adaptação e mitigação. Mas, por outro lado, eles geralmente deixam de incorporar uma variedade de aspectos potencialmente relevantes e que teriam implicações para análises regionais ou de pequena escala.

Outra mudança tecnológica importante ocorreu ao longo dos anos de 1970 e teve grande impacto na pesquisa atmosférica: o uso de satélites.

A partir da utilização mais abrangente das medições por satélites, novos programas de pesquisa da área climática foram se estabelecendo nos anos de $1970 \mathrm{e}$ 1980, vinculados a agências e instituições de pesquisa mais internacionalizadas. A Global Metereological Association (GMA), vinculada à Organização das Nações Unidas (ONU), criou a Global Atmospheric Research Programme (GARP) e o World Research Climate Programme (WRCP) (EDWARDS, 2010).

Os esforços desses programas, especialmente do WRCP, foram extremamente importantes para as medições atmosféricas mais sistemáticas e regulares. Através dele foram sendo estabelecidas formas de tratamento de dados para identificar as correlações entre atividades humanas e alterações nos padrões atmosféricos e climáticos. Segundo Edwards (2010), o WRCP promoveu as discussões iniciais que ao final da década de 1980 levaram à criação do IPCC.

A despeito desses avanços tecnológicos e dessas primeiras articulações institucionais, inexistia ainda um arcabouço organizacional mais articulado e efetivo. Os cientistas envolvidos e suas respectivas instituições se encontravam em um estágio pouco estruturado em termos de arranjos organizacionais mais sofisticados de pesquisa e compartilhamento de experiências e achados científicos que pudessem ser ajustados a uma visão global dos fenômenos climáticos (SCHOIJET, 2008; MILLER, 2004).

Esse cenário da pesquisa climática descontínua e episódica muda fortemente com as perspectivas abertas pela globalização e pela construção de espaços de discussão mundiais sobre o tema das mudanças climáticas. A partir da década de 1980 ocorreram profundas transformações nas formas organizacionais de pesquisa científica em alcance mundial que ajudaram a redefinir o cenário dos estudos climáticos e formaram novas elites da área.

\section{Novas elites climáticas da ciência}

Richard Whitley $(1977 ; 2009)$ afirma que, a partir dos anos de 1970, o ambiente organizacional das ciências atravessou um processo consistente de flexibilização e fluidez na forma de produção de conhecimentos. A dependência em relação a agenda 
militar nacionalista diminuiu sensivelmente e os interesses de agentes não universitários e não científicos passaram a ter um grande peso na definição de áreas e agendas de pesquisa.

Segundo o autor, isso levou a uma grande mudança no esquema reputacional das áreas estabelecidas. As áreas de conhecimento mais disciplinares e hierarquizadas passaram a sofrer concorrência da parte de novas ciências e temáticas até então pouco relevantes, como biotecnologia por exemplo.

No contexto anglo-saxão, principalmente, temáticas interdisciplinares que conseguiram estabelecer articulações com empresas e grupos de pressão diferenciados começaram a receber um conjunto maior de atenção e recursos, forçando uma descentralização e flexibilização do financiamento. As elites científicas tradicionais, vinculadas às áreas verticais e disciplinares, veem seu poder científico diminuir sensivelmente dentro do campo científico e precisam se readaptar.

É nesse contexto de redefinição organizacional das ciências nos países centrais que se insere o interesse crescente pelas pesquisas climáticas. Durante os anos $1980 \mathrm{e}$ toda a década seguinte, com a conscientização da temática ambiental em escala global, deu-se a construção de uma grande controvérsia em torno das mudanças climáticas. Com o arrefecimento da Guerra Fria e a globalização da economia, novas preocupações passam a se tornar prioritárias na pauta científica, em especial aquelas relacionadas às mudanças climáticas.

A partir de então, elites mundiais passaram a atuar incisivamente para disputar recursos e discursos no embate climático, superando o quadro de interesses nacionais e estratégicos do período anterior. Saem de cena as Forças Armadas, e entram as grandes corporações como articuladores da pesquisa sobre aquecimento global e mudanças climáticas.

A capacidade estratégica de financiar revistas, pagar campanhas publicitárias vultuosas e cooptar laboratórios de universidades de ponta proporcionou uma espiral de argumentações e alegações que tem origem em atores não propriamente científicos, mas que participam ativamente das controvérsias científicas com seus diferentes capitais e recursos.

Esse movimento das elites globais, cooptando setores das elites científicas emergentes, foi captado de forma clara pelo historiador David Noble (2009). Segundo ele:

Durante e última década e meia, nós temos sido submetidos a duas campanhas corporativas que competem entre si, ecoando diferentes estratégias corporativas consagradas pelo tempo e refletindo uma divisão do círculo da elite. A questão das 
mudanças climáticas tem sido contada por ambos os lados dessa elite dividida, dando a aparência de que há somente estes dois lados. A primeira campanha, que tomou forma no final da década de 1980 como parte da ofensiva da "globalização" triunfante, visava confrontar especulações sobre mudanças climáticas por meio da negação, do questionamento, da ridicularização e descartando afirmações científicas angustiantes que podem acabar com o entusiasmo na expansão do empreendimento capitalista. Essa campanha foi concebida após e, em alguma medida, construída sobre a campanha da indústria de tabaco para disseminar ceticismo sobre as crescentes evidências dos efeitos deletérios do fumo à saúde. $\mathrm{Na}$ conscientização desse esforço de propaganda negativa, todo e qualquer crítico das mudanças climáticas tem sido imediatamente identificado com este lado do debate. (NOBLE, 2009, p.16-17).

Determinados gigantes corporativos se uniram em torno da Global Change Coalition (GCC) (Coalizão para a Mudança Global), com a missão de disseminar controvérsias que freassem ou impedissem o estabelecimento de uma agenda climática mais contundente e progressista. Empresas como Dupont, Shell, Texaco, Exxon, General Motors e Ford fizeram parte desta coalizão, tendo como suporte essencial uma empresa gigante do ramo de relações-públicas, a Burson-Marsteller.

O setor automobilístico, associado aos grupos de petróleo, gás e produtos químicos produziram a controvérsia climática em sintonia com estratégias simbólicas sofisticadas. Essa coalizão foi extremamente atuante até 1997, ano que a adoção do protocolo de Kyoto foi aprovada. Três anos depois, a GCC foi encerrada e seus membros se reorganizaram em torno de outras coalizões para colocar empecilhos a ciência climática (NOBLE, 2009).

Empresas atreladas a atividades baseadas no carbono e na emissão de gases financiam e constroem sua própria elite científica e instalam grupos de pesquisadores para estabelecerem a controvérsia de que não há evidências conclusivas sobre a obrigatoriedade e o alcance das mudanças climáticas.

As grandes corporações, aliadas a lideranças científicas bem posicionadas nas instituições acadêmicas de prestígio dispunham de recursos e alianças que permitiram, nas décadas de 1990 e 2000, alimentar a controvérsia em proveito próprio. Há diversos casos de controvérsias acadêmica e jurídica envolvendo pesquisadores, mídia e financiamento privado dessas controvérsias (ORESKES \& CONWAY, 2010).

Os cientistas com acesso privilegiado às esferas de poder político conseguiram durante um tempo considerável impedir o reconhecimento pelo público dos grandes problemas envolvendo as emissões de gases e o aumento médio de temperaturas. Um grupo bem coeso de físicos com trânsito facilitado nas altas esferas de poder norte- 
americano foram capazes de construir uma convergência sólida que impactou no debate científico dos anos de 1980, reabilitando as fórmulas de segredo e representação geopolítica da Guerra Fria.

"Seitz, Jastrow, Nierenberg e Singer tinham acesso ao poder - até a Casa Branca - em virtude de suas posições enquanto físicos vencedores da Guerra Fria. Eles usaram esse poder para sustentar sua agenda política, mesmo que isso significasse atacar a ciência e seus colegas cientistas, evidentemente acreditando que seus fins maiores justificassem seus meios. Talvez isso também fosse parte de seu legado profissional...Após a Guerra Fria, a maioria dos cientistas estava satisfeita por se ver livre das imposições do segredo e das informações falsas mas Seitz, Singer e Nierenberg continuavam a se comportar como se a Guerra Fria não tivesse acabado" (ORESKES \& CONWAY, 2010, p.199-200). (tradução nossa) ${ }^{1}$.

Se nos anos de 1980 e 1990 as grandes corporações participaram das controvérsias negando em larga escala a ocorrência das mudanças climáticas através de seus aliados (cientistas, revistas), na década seguinte ocorreu uma forte mudança de posição.

Setores hegemônicos do mundo corporativo perceberam que as questões colocadas pelo Protocolo de Quioto (1997) e pelos grupos antiglobalização exigiam uma resposta mais assertiva e propositiva e com base acadêmica. Eles iniciaram então uma campanha positiva, procurando

[...] apropriar-se do tema ambiental para moderar suas implicações políticas, desse modo tornando-a compatível com os interesses econômicos, geopolíticos e ideológicos das corporações. A campanha climática corporativa dessa maneira enfatizou a primazia das soluções "fundadas no mercado" enquanto insistia na uniformidade e na previsibilidade de regras obrigatórias e regulações. (NOBLE, 2009, p.17).

\footnotetext{
${ }^{1}$ Seitz, Jastrow, Nierenberg, and Singer had access to power-all the way to the White House-by virtue of their positions as physicists who had won the Cold War. They used this power to support their political agenda, even though it meant attacking science and their fellow scientists, evidently believing that their larger end justified their means. Perhaps this, too, was part of their professional legacy...After the Cold War, most scientists were relieved to be freed of the burdens of secrecy and misrepresentation, but Seitz, Singer, and Nierenberg continued to act as if the Cold War had not ended. (ORESKES \& CONWAY, 2010, p.199-200).
} 
A manutenção de uma postura de negação e esquivamento da problemática climática representava nos anos de 1990 uma postura anacrônica frente às discussões que a comunidade científica colocava na agenda. No início dos anos 2000, uma nova coalizão foi oficialmente montada em torno do Partnership for Climate Action (PCA) (Associação para Ações Climáticas). Um dos líderes dessa coalizão era a Goldman Sachs, que incluía também Dupont, Shell, Alcan, Pechiney, entre outras empresas de destaque.

Entre várias iniciativas, essa coalizão abriu novas frentes de pesquisa científica voltadas à diminuição de emissão de gases e melhor aproveitamento energético. Pesquisas com células voltaicas, etanol, energia eólica e solar são exemplos de novas atividades técnico-científicas construídas e legitimadas a partir de novos entendimentos da problemática do clima.

A adesão de movimentos sociais às preocupações climáticas e a necessidade dos governos nacionais se legitimarem frente às suas bases de apoio político e econômico foram responsáveis pelo fortalecimento e aceitação generalizada de argumentos científicos que num período anterior eram desacreditados e pouco transmitidos. Era necessária a conformação de uma nova convergência em torno dessa matéria do clima, de modo a apresentar respostas convincentes e elaborar propostas factíveis (MILLER, 2004).

\section{O IPCC como aglutinador da elite climática mundial}

No ano de 1988 a ciência climática passou a adquirir uma conformação institucional diferenciada. Foi então criado no âmbito das Nações Unidas o IPCC, aglutinando cientistas de renome oriundos de diferentes áreas de conhecimento e sendo responsável pela elaboração de diversos relatórios que acabaram por adentrar na agenda das agências internacionais e convenceram governos, agentes econômicos e o público em geral das implicações atuais das mudanças do clima. Vários trabalhos têm apresentado as controvérsias presentes no IPCC, em virtude de seus vieses disciplinar e geopolítico, bem como as deficiências contidas nos achados científicos dos relatórios (MILLER, 2004).

Em diversos aspectos, as formas de trabalho e as implicações entre ciência e formulação de políticas no interior do IPCC seguem padrões estabilizados e convencionais. Segundo Yearley (2009), as regras de revisão pelos pares, dos materiais produzidos pelo IPCC não conseguem fugir aos padrões estabelecidos na comunidade científica, especialmente entre as áreas mais convencionais e consagradas. 
A reprodução de membros entre pesquisadores e avaliadores, a seleção de áreas legítimas e a perpetuação de práticas científicas tendem a marcar o funcionamento do IPCC, apesar de suas propaladas inovações em termos de debate coletivo.

\begin{abstract}
"Se desafiado o IPCC tenderia a recuar, usando o roteiro clássico de "ciência para políticas públicas"...; o IPCC se legitimou a partir da objetividade científica e da imparcialidade de seus membros. Mas os críticos eram capazes de apontar que as carreiras científicas dos "ortodoxos" das mudanças climáticas dependiam da sua submissão às posições básicas. Pior ainda, o IPCC e os formuladores de políticas em grande medida selecionavam quem entrava no grupo dos especialistas qualificados e, portanto, ameaçavam se tornar uma comunidade que se auto perpetuava com o interesse velado de continuar a encontrar evidências para a importância dos fenômenos aos quais as carreiras dos seus membros estavam algemadas (YEARLEY, 2009, p.396). (tradução nossa)2.
\end{abstract}

Em certo sentido o IPCC traz aspectos de uma coalizão científica aparentemente nova e portadora de promessas de discussão abertas e complexas. Por outro lado, o Painel corre o risco de perpetuar grupos estabelecidos e áreas disciplinares portadoras de uma capacidade superior de modelar e antecipar tendências.

Utilizando outra abordagem da sociologia da ciência, é possível afirmar que o IPCC traz uma nova forma de coalizão transversal da elite climática em escala global, que só poderia ter se constituído dos anos de 1980 em diante.

De acordo com Beck (2012), o painel teve que criar inovações procedimentais de forma a ajustar um conhecimento ao mesmo tempo consistente e respeitável por um lado, e viável politicamente por outro. Isso cria desafios em termos da conformação de uma expertise efetiva em termos de autoridade científica global, o que não impede que determinadas áreas de conhecimento formem a base de sustentação epistemológica.

A composição do IPCC, o funcionamento dos Grupos de Trabalho e as articulações globais que conduziram a organização dos relatórios mostram claramente um aspecto fundamental: a ausência de um fio condutor único e impositivo na apresentação dos achados científicos e a aleatoriedade da formação de equipes e

\footnotetext{
${ }^{2}$ If challenged, the IPCC tended to fall back in line with the classic script of 'science for policy'...; the IPCC legitimated itself in terms of the scientific objectivity and impartiality of its members. But critics were able to point out that the scientific careers of the whole climate change 'orthodoxy' depended on the correctness of the underlying assumptions. Worse, the IPCC and policy-makers largely selected who was in the club of the qualified experts and thus threatened to be a self-perpetuating community with a vested interest in continuing to find evidence for the importance of the phenomenon to which its members' careers were shackled [...]. (YEARLEY, 2009, p.396).
} 
temáticas ao longo do tempo. Vários autores que discutem o histórico do IPCC apontam que entre um relatório e outro percebe-se que equipes e assuntos se modificam, assim como o impacto que os achados trazem para a imprensa e opinião pública são imprevisíveis e aleatórios (SCHOIJET, 2008; MILLER, 2004).

A legitimidade do IPCC e sua aceitação na comunidade científica e política dependem exatamente desse revisionismo constante, que se justifica por uma série de circunstâncias conjunturais e negociadas. Segundo Shinn (2000), o regime transversal da ciência contemporânea significa exatamente que um amplo conjunto de atores científicos e não científicos são chamados a criar grupos intersticiais de atuação que se notabilizam pela concepção e implementação de instrumentos genéricos e protocolos de ação.

Essas comunidades abdicam de uma interferência pura ou desinteressada no universo científico ou político, ou em determinadas disciplinas ou instituições, mas apostam suas fichas na edificação universal de princípios de gestão modelizados. Com isso, procuram inserção em espaços pouco estabelecidos em termos hierárquicos tradicionais, de modo que possam reconverter seus capitais próprios no interior de novos formatos e associações cambiantes.

É possível perceber um esforço institucional e analítico das diferentes áreas de conhecimento para articular conhecimentos e ferramentas de pesquisa de modo a poder atender as demandas de temática tão complexa, embora existam dificuldades para que essa agenda seja incorporada por ciências periféricas.

Nessas, ainda prevalece um forte viés disciplinar, apesar da necessidade de estabelecer uma prática transdisciplinar de pesquisa para se lidar com as mudanças climáticas. A manutenção de uma postura disciplinar rígida ocorre muitas vezes pela necessidade que as ciências humanas sentem em se fortalecerem no cenário científico. Caso elas embarquem em grupos interdisciplinares de pesquisa, correm o risco de terem sua contribuição diminuída em relação às ciências mais estabelecidas.

Segundo Yearley (2009), apesar dos esforços de áreas subalternas em se posicionar na produção de análises climáticas, as regras rígidas de hierarquização continuam em ação. Analisando a formatação dos grupos que atuam no IPCC, o autor detecta que as ciências sociais são incorporadas no rótulo da economia, tornando suas análises submetidas ao viés dos instrumentos de mercados e projeções de cenários. As contribuições das ciências sociais são na maior parte das vezes inscritas no rol de análise dos "impactos" das mudanças climáticas, e não no âmbito da predição e formulação de modelos.

Esse é um aspecto gerador das hierarquias disciplinares, mais do que uma fórmula de integração. Na visão desse autor, o modo com que a elite do IPCC conforma 
as ciências humanas no interior da comunidade do clima preestabelece sua contribuição e forma de leitura: "O aspecto da "construção" que é de interesse específico aqui é a construção do papel das ciências sociais. A participação das ciências sociais no IPCC se dá na "posição inferior", lidando com as consequências e impactos da ciência climática" (YEARLEY, 2009, p.400-401)3. (tradução nossa).

A produção da crença de que as ciências sociais só podem atuar no âmbito dos impactos ambientais interfere fortemente em sua posição dentro das ciências efetivamente necessárias para a produção de modelos climáticos. Segundo Bourdieu (2011), o monopólio da interpretação da inserção dos novatos no interior do campo é conduzido pelos agentes que produzem as classificações. Nesse sentido, as ciências sociais e seus congêneres precisam incorporar novas crenças à sua forma de representação no interior do campo climático de modo a almejar um reconhecimento superior.

Para as elites climáticas em busca de ascensão e reconhecimento, o formato organizacional do IPCC significa um espaço aberto em termos da construção de oportunidades de integração e associação. Sem se submeter a instituições impositivas e altamente hierárquicas como universidades, Forças Armadas ou grandes corporações, os cientistas do clima encontram no IPCC uma agenda móvel e flexível que os permite circular nacional e internacionalmente variando suas estratégias e formas de acumulação de capital. Atualmente o IPCC representa o organismo transversal mais propício para que as elites climáticas exercitem seu capital em busca de fortalecimento científico e reputacional.

É importante salientar, como Hughes (2015) faz, que a montagem organizacional do painel leva que os grupos dominantes se articulem com as instâncias de administração e avaliação interna do grupo, fortalecendo ainda mais o capital científico predominante.

"A luta pelo capital científico não apenas estrutura as relações internas e entre o bureau e o painel. A autoridade científica define a ordem das relações entre as equipes e os Grupos de Trabalho, e se tornou um objeto de disputa entre as Unidades de Suporte Técnico e a secretaria. Conhecimento científico sobre a questão das mudanças climáticas e o conhecimento da prática do processo de avaliação são fontes importantes de capital intelectual para todos os atores no interior do IPCC. Esse capital intelectual é particularmente útil para os agentes governamentais durante as reuniões plenárias do

3 "The aspect of the 'construction' that is of particular interest here is the construction of social science's role. The IPCC's involvement of social science is on the 'downstream' side, dealing with the consequences and impacts of climate science." (YEARLEY, 2009, p.400-401). 
IPCC e aprovação dos Resumos para Formuladores de Políticas, quando os delegados traduzem esse conhecimento para interposições recorrentes e embasadas para alteração do texto proposto (HUGHES, 2015, p.17) (tradução nossa) ${ }^{4}$.

A formação dessas coalizões ilustra claramente como o estabelecimento de elites científicas na área climática ocorre mediante o ajuste às exigências do ambiente organizacional vigente. À medida que o campo científico constrói novas formas de aderência às instituições circundantes, as fórmulas de acumulação de capital e crédito reputacional por parte das elites acadêmicas adquirem uma dinâmica mais complexa e ajustada, o que demanda novas ferramentas analíticas.

\section{Ciência climática no Brasil}

No Brasil, é possível identificar como as lideranças científicas se organizaram em torno da discussão climática. Em 1950 a ONU criou a Organização Meteorológica Mundial (OMM), uma agência voltada a cooperação e intercâmbio de dados meteorológicos entre os países-membros. Desde o início o Brasil se afiliou à OMM e outros grupos internacionais de estudos climáticos, apesar das assimetrias em termos técnicos e de pessoal em relação aos países mais avançados. Uma das deficiências mais salientes referia-se à falta de mão de obra qualificada para os estudos meteorológicos, que se tornavam cada vez mais sofisticados e dependentes de conhecimentos na área de modelagem e sistemas informacionais complexos.

Entre o final da década de 1950 e início do período seguinte foram tomadas medidas para sanar a deficiência de pessoal qualificado. Havia a percepção no campo de que não era mais possível acompanhar o ritmo da evolução das ciências climáticas internacionais sem a formação de uma comunidade específica de pesquisadores (OLIVEIRA, 2009).

Esse campo, de forma ainda intermitente e instável, se mobilizou para se estabelecer cientificamente. No ano de 1958 foi criada a Sociedade Brasileira de Meteorologia (SBMET), com a finalidade de agregar os meteorologistas existentes e

\footnotetext{
${ }^{4}$ The struggle for scientific capital not only structures relations within and between the bureau and the panel. Scientific authority defines the order of relations within chapter teams and WGs, and has become an object for struggle between the TSUs and the secretariat. Scientific knowledge of the climate change issue and knowledge of the assessment process in practice are important sources of intellectual capital for all actors within the IPCC. This intellectual capital is particularly valuable to member governments during IPCC plenary meetings and approval of the SPMs, when delegates translate this knowledge into frequent and authoritative interventions for altering proposed text. (HUGHES, 2015, p.17).
} 
regulamentar a profissão no país. Seu primeiro presidente foi Fernando Pimenta Alves, que havia entrado na área de meteorologia por ter feito cursos internacionais em convênio com o Instituto Brasil - Estados Unidos. Por conta do período político conturbado, no início dos anos de 1960 a SBMET foi desativada, sendo reorganizada posteriormente em 1976.

Durante o governo JK (1956-1960) foi lançado pelo Ministério da Educação e Cultura um movimento específico: a Campanha de Formação de Meteorologistas, o CAME.

Atendendo a demanda urgente estabelecida pelo campo climático internacional teve início, através do CAME, um processo de discussão, administrativo e acadêmico, sobre a formação de pessoal técnico na área de meteorologia no país.

No governo João Goulart (1961-1964) foram estabelecidas as bases para a organização dos cursos de meteorologia. Foi feita uma articulação entre o Ministério da Agricultura, o Serviço de Meteorologia a ele associado, e setores importantes da área da física para viabilizar os cursos.

Como resultado desse esforço lançado pelo CAME, o primeiro curso de graduação em meteorologia no Brasil foi criado em 1964, na Universidade do Brasil hoje Universidade Federal do Rio de Janeiro (UFRJ) -, em uma forte articulação entre os campos científico e político do momento. Segundo Pereira e Spinardi (2003), os agentes ficaram assim representados:

A Campanha de Formação de Meteorologistas, neste ato representada pelo diretor de Ensino Superior do Ministério da Educação e Cultura, professor Durmeval Trigueiro Mendes, daqui por diante designada CAME, e a Faculdade Nacional de Filosofia, Ciências e Letras da Universidade do Brasil, representada pelo seu diretor, professor José de Faria Góes Sobrinho, daqui por diante designada Faculdade, e o Centro Brasileiro de Pesquisas Físicas (CBPF), representado pelo seu vice-presidente em exercício, dr. Almir de Castro, anuem em assinar o presente acordo, destinado a manter um curso de meteorologia, bem como incentivar o aperfeiçoamento e a difusão da ciência meteorológica. (PEREIRA; SPINARDI, 2003, p.142).

A participação do CBPF e do Departamento de Física da universidade na formação e no funcionamento do curso oferece um forte indício da importância dos estudos da física na área meteorológica nessa nova configuração.

Em consonância com os rumos da ciência climática internacional, o campo de ciências do clima brasileiro acompanha suas tendências e áreas hegemônicas, tornando as áreas de física e computação setores estratégicos. 
Essa conquista de posições das áreas de física e informática era necessária para tornar a pesquisa climatológica brasileira sintonizada a determinadas áreas de conhecimento com forte interface internacional, especialmente da moderna climatologia americana. De acordo com Miguel (2017),

[...] a crescente articulação de instituições meteorológicas internacionais conectadas à OMM não teria sucesso se o grande volume de dados coletados em áreas dispersas do globo não pudesse ser processado e analisado rapidamente. Isso se tornou possível mediante aos avanços na área da computação e modelagem. Sem os modelos, o grande volume de dados coletados e compartilhados não teria utilização prática para os serviços meteorológicos porque não se poderia assimilar essas informações rapidamente e produzir previsões meteorológicas em tempo útil ao público. Ao receberem os dados das centrais de telecomunicação, os modelos produzem o diagnóstico do "estado atual" da atmosfera - o que os profissionais da área chamam de "assimilação de dados" - e, posteriormente, calculam a evolução desse estado atmosférico no tempo produzindo assim as previsões do tempo e clima. (MIGUEL, 2017, p.62-63).

Ocorreu uma expansão global das técnicas de armazenamento e análise de dados climatológicos que precisavam ser manipulados em diferentes países, forçando o campo científico periférico a se adaptar rapidamente em termos infraestruturais.

Nos anos de 1960, outra área científica ligada às ciências físicas passou a ser essencial para o campo climático: a questão espacial. $\mathrm{O}$ uso de satélites nas medições atmosféricas obteve importância estratégica, exigindo dos pesquisadores da área uma adaptação às linguagens e formas de análises de dados gerados por esses meios. A formação contínua de bases de dados e os meios de recepção e compartilhamento de informações advindas de satélites intercontinentais, dentro das novas redes meteorológicas, tornavam o campo climático dependente de acordos internacionais e protocolos de participação em consórcios de pesquisa.

Segundo Miguel (2017, p.64)), a pesquisa meteorológica brasileira, em sua incipiência em termos de formação de pessoal e arcabouço tecnológico, enfrentou vários problemas para acompanhar essa movimentação específica do campo climático internacional, pois "somente na década de 1970 foram instaladas em Brasília as primeiras estações de recepção de satélites meteorológicos e uma rede básica de observação e telecomunicação que incluía o país nos circuitos de transferência de dados dos Centros Meteorológicos Mundiais da OMM".

As condições infraestruturais para o compartilhamento de grande massa de dados em alta velocidade excediam a capacidade instalada no país, que até então possuía 
poucas instituições de pesquisa na área espacial. Centros de pesquisa importantes, como o Instituto de Pesquisas Espaciais (INPE) e a Empresa Brasileira de Telecomunicações (EMBRATEL) eram recentes e ainda pouco aparelhadas para fazer frente a essas demandas tecnológicas.

Vinculado ao Ministério da Agricultura, o Instituto Nacional de Meteorologia (INMET) consistia no principal centro de estudos meteorológicos, reconhecido no país e na América Latina. Fundado em 1909 e contando historicamente com grande suporte governamental, como visto acima, o Instituto congregava um grande número de pesquisadores e dados coletados. O representante brasileiro na OMM era indicado pelo Instituto, o que conferia uma legitimidade considerável no campo em âmbito nacional. Apesar disso, seus serviços meteorológicos eram atrasados em relação aos centros mundiais (OLIVEIRA, 2009).

Até a década de 1980 o INMET teve capacidade limitada para compra de equipamentos e formação de pessoal capacitado, não conseguindo estabelecer uma expertise sólida e bem articulada, necessária para o intercâmbio de dados nas redes de pesquisa internacionalizadas.

O campo climático em construção sentia a necessidade de definir algum centro de pesquisa meteorológica nacional para concentrar nele capital científico e construir um polo que agregasse investimentos e força política. A forte internacionalização dessa área de pesquisa e sua demanda contínua por especialização e atualização tecnológica exigia a formação de um grupo de excelência acadêmica que se colocasse como interlocutor nacional frente às agências que controlam a agenda. Esse polo aglutinador seria naturalmente o INMET por sua história e por sua consagração no interior do campo.

Encontros realizados nos anos de 1980 pela SBMET indicavam o INMET como forte candidato a receber investimento financeiro e científico para posicionar a ciência climática brasileira internacionalmente, como a elite da área climática.

No entanto, não foi isso o que aconteceu. Contrariando uma expectativa gestada no interior do campo climático, a instituição que logrou se consagrar como detentora de capital científico diferenciado foi o Centro de Previsão de Tempo e Estudos Climáticos (CPTEC), vinculado ao INPE, do estado de São Paulo.

As elites do campo científico tiveram um papel essencial nessa nova convergência climática. O posicionamento favorável de seus principais expoentes, como o diretor do INPE Marco Antônio Raupp, e as fortes ligações com o MCT sob o comando de Renato Archer influiu para que o INPE abrisse caminho entre as agências e fóruns científicos, dando espaço privilegiado ao CPTEC enquanto interlocutor qualificado. 
No ano de 1987 foi dado um passo fundamental para a implantação do CPTEC com a produção de documento por parte de um grupo de trabalho instituído no âmbito do MCT para reorganizar a pesquisa meteorológica no interior do INPE e aprovação pelo governo Sarney (1985-1990). (BRASIL, 1987).

O processo de organização do CPTEC foi estabelecido claramente a partir da experiência dos membros em espaços internacionais de pesquisa climática. Durante o período de construção institucional, os cientistas brasileiros responsáveis visitaram e importaram modelos já estabelecidos. Segundo Miguel, Escada e Monteiro (2016),

[...] entre 1986 e 1987, pesquisadores do INPE foram enviados ao Met Office, do Reino Unido, Centro Europeu de Previsões de Tempo de Médio Prazo (ECMWF), em Reading, na Inglaterra, e ao NCEP, nos Estados Unidos, para conhecer o funcionamento destes centros. Decidiu-se que o modelo institucional a ser adotado no CPTEC seria um similar ao do ECMWF, cuja estrutura de funcionamento sustentava-se em dois setores: operação e pesquisa, que deveriam atuar em conjunto, interagindo com o intuito de gerar e aperfeiçoar sistematicamente as previsões de tempo e clima. (MIGUEL; ESCADA; MONTEIRO, 2016, p.40).

Foi através dessas visitas e da realização de capacitação acadêmica em programas de pós-graduação no exterior que se construíram os vínculos necessários para o estabelecimento de uma nova elite climática no país. É perceptível nesse processo a proeminência dos agentes com formação acadêmica no estabelecimento dessa agenda de pesquisa institucional diferenciada.

Segundo a abordagem relacional de Bourdieu (2002), os agentes do campo acadêmico em contextos periféricos procuram viabilizar seus empreendimentos científicos e acumular seu capital construindo legitimidades por intermédio de diferentes expedientes. Um deles se dá por meio da circulação internacional de práticas e conhecimentos científicos, que permitem sacralizar as teorias, práticas e métodos oriundos dos centros produtores, ao mesmo tempo, de conhecimento e reconhecimento. Porém, ao invés de se constituir um mercado aberto e liberal de ideias, essa circulação internacional é feita de barreiras e filtros nacionais e científicos. Para Bourdieu (2002), existe um conjunto de premissas e regras que devem ser levadas em conta pois,

[...] a transferência de um campo nacional para um outro se faz por meio de uma série de operações sociais: uma operação de seleção (o que se traduz? O que se publica? Quem traduz? Quem publica?); uma operação de marcação (de um produto anteriormente "sem etiqueta") pela editora ([...] e anexando-a a seu próprio ponto de vista e, em todo caso, a uma problemática inscrita no campo de 
chegada e que só raramente realiza o trabalho de reconstrução do campo de origem, em primeiro lugar porque é muito difícil); uma operação de leitura, enfim, com os leitores aplicando à obra categorias de percepção e problemáticas que são produto de um campo de produção diferente.” (BOURDIEU, 2002, p.18).

As fórmulas e estratégias de certificação dos conhecimentos científicos diferenciados, ao serem exportados para outros lugares, implicam em uma readequação de propósitos e realinhamento dos agentes portadores e disseminadores da ciência. É nesse momento de transmissão que o campo se reordena para consagrar os porta-vozes qualificados e estabelecer as hierarquias acadêmicas.

A capacidade do CPTEC em se alinhar às expectativas do campo e se posicionar favoravelmente nas disputas de capital científico específico levaram a uma redefinição de prioridades e estratégias dos atores. Apesar de ser uma instituição mais jovem, fundada nos anos 1990, e com menos tradição nas linhas da meteorologia brasileira, o CPTEC aglutinou em seu entorno uma gama de características e modalidades de comportamento científico e político que o alçaram a vanguarda meteorológica da América Latina.

A mudança dos centros de referência dos estudos climáticos mostra claramente a reorganização das elites do clima no Brasil, em sintonia com as tendências internacionais.

\section{Algumas conclusões}

É importante notar que as ciências climáticas acompanharam transformações que ocorreram no conjunto das práticas intelectuais hegemônicas. O estabelecimento de tecnologias globais; a criação de periódicos de divulgação científica em escala mundial conectando as elites universitárias, os interesses estratégicos dos estados nacionais e a criação de agências internacionais foram aspectos centrais na ampliação do conhecimento científico das questões do clima.

Não é coincidência que os países centrais do capitalismo em expansão, como Inglaterra, França, EUA e Alemanha foram protagonistas do desenvolvimento dessas formas de conhecimento e abordagens sobre os fenômenos climáticos. As condições financeiras privilegiadas e o grande desenvolvimento das instituições científicas desses países nos séculos XIX e XX favoreceram o incremento de pesquisas altamente dependentes de armazenamento de informações, coleta de dados em forma descentralizada e modelos computacionais. 
A imposição generalizada de um modo organizacional das universidades europeias acarretou a concentração de recursos teóricos e princípios metodológicos que se consagraram mundialmente. Junto com isso, a hegemonia das ciências exatas e aplicadas ao longo desse período trouxe o estabelecimento organizado de elites científicas bem posicionadas junto aos Estados e agências internacionais.

$\mathrm{O}$ resgate da trajetória da ciência climática mostra que o posicionamento dos cientistas e pesquisadores no sistema científico tem um efeito considerável sobre a possibilidade de sua aceitação tanto junto aos pares, como a um público diferenciado. As transformações dos arranjos organizacionais da ciência climática mostram que os grupos dominantes precisam se adaptar e recriar estratégias para a manutenção de seu capital e condição reputacional.

O estudo das elites científicas e acadêmicas, em suas interfaces com os agentes que atravessam o campo, possibilitam identificar alguns indícios das estratégias mobilizadas pelos agentes e as possibilidades de interface com o Estado e outras instituições relevantes. É importante salientar que os estudos de elites científicas que enfatizam preferencialmente as regras internas do campo e as estratégias de conversão de capital institucional legítimo falham por não interpelarem eficazmente o conjunto do cenário científico e não científico relacionado a uma dada área de conhecimento.

Os estudos sobre as ciências climáticas, em sua diversidade de campos, subcampos e especializações, têm grande chance de trazerem um melhor entendimento sociológico sobre sua importância no sistema de ciências, caso incorporem a perspectiva transversal da produção de seus grupos dominantes, tarefas e instituições correspondentes.

Essa expectativa se fundamenta na produção de um número crescente de autores que propagam esse olhar transversal em diferentes contextos científicos e organizacionais. Tomara que os estudos climáticos recebam mais contribuições desse tratamento sociológico, pois são fundamentais no contexto atual em termos políticos e sociais, tanto em escala nacional como internacional.

\section{SCIENTIFIC elites OF THE CLIMATE: ShapING OF THE FIELD IN NATIONAL AND INTERNATIONAL SCALE}

ABSTRACT: This article aims to discuss the importance of climate sciences and their current conformation, arguing that it is important to return to the theme of scientific elites to understand the current directions of the discussion on climate change. Bourdieu's approach on the subject of the scientific field and the forms of capital 
accumulation helps to understand changes in meteorological sciences in the face of the most recent challenges of climate change in the last decades. The text analyzes the development of climate sciences on an international scale and the role played by the International Panel for Climate Change (IPCC) in the redistribution of established scientific credits in the area. At the end, the text deals with the way the Brazilian elites have been reorganizing themselves to face the international hegemonic sectors which command the research agenda on climate change.

KEYWORDS: Scientific elites. Climate sciences. Science field. Climate change.

\section{ELITES CIENTÍFICAS DEL CLIMA: FORMACIÓN DEL CAMPO A ESCALA NACIONAL E INTERNACIONAL}

RESUMEN: Este articulo tiene como objetivo discutir la importancia de las ciencias climáticas y su conformación actual, argumentando que es importante volver al tema de las élites cientificas para comprender las direcciones actuales de la discusión sobre el cambio climático. El enfoque de Bourdieu sobre el tema del campo científico y las formas de acumulación de capital ayuda a comprender los cambios en las ciencias meteorológicas frente a los desafíos más recientes del cambio climático en las últimas décadas. El texto analiza el desarrollo de la ciencia del clima a escala internacional y el papel que desempeña el Panel Intergubernamental sobre Cambio Climático (IPCC) en la redistribución de los créditos científicos consagrados en el área. Al final, el texto trata sobre la forma en que las élites brasileñas se han ido reorganizando para enfrentar a los sectores hegemónicos internacionales que dominan la agenda de investigación sobre cambio climático.

PALABRAS ClaVE: Élites cientificas. Ciencias climáticas. Campo científico. Cambios climáticos.

\section{REFERÊNCIAS}

BAILÃO, André. Ciências e mundos aquecidos: narrativas mistas de mudanças climáticas em São Paulo. Orientador: Stelio Marras. 2014. 227 f. Dissertação (Mestrado em Antropologia Social) - Faculdade de Filosofia, Letras e Ciências Humanas, Universidade de São Paulo, 2014. 
BECK, Silke. The challenges of building cosmopolitan climate expertise: the case of Germany, WIREs Clim Change, 3, p.1-17, 2012.

BESSAT, Fréderic. A mudança climática entre ciência, desafios e decisões: olhar geográfico, Terra Livre, vol. I, n. 20, jan/jul. 2003.

BOURDIEU, Pierre. Para uma sociologia da ciência. Lisboa: Edições 70, 2004.

BOURDIEU, Pierre. As condições sociais da circulação internacional das ideias, Enfoques Revista Eletrônica, v.1, n. 01, 2002.

BOURDIEU, Pierre. O campo científico. In: ORTIZ, R. (org) Pierre Bourdieu: sociologia. São Paulo: Ática (Coleção Grandes Cientistas Sociais), 1983. p.122-155.

BOURDIEU, Pierre. Homo academicus, Florianópolis: Ed. UFSC, 2011.

BRASIL. Ministério da Ciência e Tecnologia. Comissão Nacional de Meteorologia. Grupo de Trabalho de criação do Centro de Previsão de Tempo e Estudos Climáticos, e do Centro de Aplicação de Satélites Meteorológicos - Relatório Final. Brasília: MCT, 1987.

DESSAI, Suraje \& TRIGO, Ricardo. A ciência das alterações climáticas. Finisterra, XXXVI, 71, p.117-132, 2001.

DOEL, Ronald. Constituting the Postwar Earth Sciences: The Military's Influence on the Environmental Sciences in the USA after 1945. Social Studies of Science, v. 33, 5: p. 635-666, 2003.

EDWARDS, Paul. A vast machine - computer models, climate data and the politics of global warming, Cambridge: MIT Press, 2010.

HAMBLIN, Jacob Darwin. Arming mother nature: the birth of catastrophic environmentalism. Oxford: Oxford University Press, 2013.

HUGHES, Hannah. Making up the Intergovernmental Panel on Climate Change (IPCC), Paper presented at the Workshop on Environment and Security, Université Libre de Bruxelles (August 28-29th, 2015).

HULME, Mike. How Climate Models Gain and Exercise Authority. In: HASTRUP, Kirsten; SKRYDSTRUP, Martin. (eds.) The Social Life of Climate Change Models: Antecipating Nature. New, York, Routledge, 2013. p.30-44.

LAHSEN, Mayanna. Seductive Simulations? uncertainty distribution around climate models. Social Studies of Science, v. 35, p.895-922, 2005.

LEITE, José Corrêa. Controvérsias na climatologia: o IPCC e o aquecimento global antropogênico. Scientiæ Studia, São Paulo, v. 13, n. 3, p.643-77, 2015.

MIGUEL, Jean Carlos. Políticas e infraestruturas das ciências atmosféricas: um estudo social da modelagem climática no INPE. Orientador: Marko Synesio Monteiro. 2017. $244 f$. 
Tese (Doutorado em Política Científica e Tecnológica) Instituto de Geociências, Universidade Estadual de Campinas, Campinas, 2017.

MIGUEL, Jean Carlos; ESCADA, Paulo; MONTEIRO, Marko Synesio. Políticas da Meteorologia no Brasil: trajetóriase disputas na criação do CPTEC. Revista Brasileira de História da Ciência, Rio de Janeiro, v. 9, n. 1, jan/jun, p.36-50, 2016.

MILLER, Clark. Climate Science and the making of a global political order. In: JASANOFF, Sheila (ed) States of knowledge. New York: Routledge, 2004. p.46-66.

NEVES, Fabrício \& LIMA, João Vicente. As mudanças climáticas e a transformação das agendas de pesquisa, Liinc em Revista, v.8, n.1, março 2012.

NOBLE, David. O golpe climático corporativo. In: ALMEIDA Jr., Antônio \& ANDRADE, Thales. (orgs) Mídia e Ambiente: estudos e ensaios. São Paulo: Hucitec, 2009. p.15-28.

OLIVEIRA, Fabíola. INMET: 100 anos de Meteorologia no Brasil. Brasília: Edição Independente, 2009.

ORESKES, Naomi; CONWAY, Erik. Merchants of doubt - how a handful of scientists obscured the truth on issues from tobacco smoke to global warming, New York: Bloomsbury Press, 2010.

PEREIRA, Vera Malfa.; SPINARDI, Alcir. Memórias do Tempo - um livro sujeito a chuvas e trovoadas. São Paulo: Edição Independente, 2003.

SAINT MARTIN, Monique. Da reprodução à recomposição das elites: as elites administrativas, econômicas e políticas na França, Tomo, n. 13, jul/dez 2008.

SCHOIJET, Maurice. Límites del crecimiento y cambio climático. México, D.F.: Siglo XXI, 2008 .

SHINN, Terry. Formes de division du travail scientifique et convergence intelectuelle, Revue Française de Sociologie, v. 41, n. 03, 447-473, 2000.

SUNDBERG, Mikaela. Making Meteorology: social relations and scientific practice.

Stockholm: Sweden, 2005.

VELTRONE, Allan. Interdisciplinaridade na Questão Climática: a participação das Ciências Sociais no Painel Intergovernamental de Mudanças Climáticas (IPCC). Orientador: Thales de Andrade. 2017. 181f. Tese (Doutorado em Ciência, Tecnologia e Sociedade), Centro de Educação e Ciências Humanas, Universidade Federal de São Carlos, São Carlos, 2017.

VESSURI, Hebe \& ROSE, Isabel. Las Fronteras de la Ciencia y un Nuevo Contrato Social con la Universidad: el ejemplo del cambio climatico. Educacion Superior y Sociedad, 15(1), p.179-197, 2010.

WHITLEY, Richard. The intellectual and social organization of the sciences. New York: Oxford University Press, 2009. 
WHITLEY, Richard. Changes in the social and intellectual organization of the sciences. In: MENDELSOHN, Everett.; WEINGART, Peter \& WHITLEY, Richard. The social production of scientific knowledge. Dordrecht: Reidel, 1977.

YEARLEY, Steven. Sociology and Climate Change after Kyoto - What Roles for Social Science in Understanding Climate Change? Current Sociology, Vol. 57(3), May, p.389-405, 2009.

Recebido em 11/11/2019.

Aprovado em 21/08/2020. 